\title{
A Review of Men's Health Curricula in Medical Schools
}

\author{
Andries J Muller*, Vivian R Ramsden, Gill White \\ Academic Family Medicine, Saskatoon, SK, University of Saskatchewan, Canada \\ *Corresponding author: a.muller@usask.ca \\ Received January 06, 2013; Revised May 02, 2013; Accepted May 03, 2013
}

\begin{abstract}
The goal of this review was to search for information about postgraduate education in medical schools and family medicine residency training programs on the topic of men's health. The databases Medline, Embase, Web of Science, Scopus and PubMed were searched using MeSH terms such as "male", "health education", "curriculum" and "family physician" and "general practitioner". Other types of literature and ephemera were also reviewed using the same search terms. With the help of a health librarian at the University of Saskatchewan, three articles were identified initially. By exploring the references of these articles as well as with documents found on various websites, a total of 108 articles and nine textbooks were in the end reviewed. The literature that were found, were divided and analyzed in three distinct categories: curriculum in general, Family Medicine curriculum in Canada and the current status of men's health training in the world. There is a paucity of literature on the topic of men's health education in Canada. Other countries such as Australia have done some work in this field but the details of the specific curriculums are lacking.
\end{abstract}

Keywords: male, health education, curriculum, family physician

\section{Introduction}

Men die younger than women - that is just a fact $[1,2]$ It is also true for the Canadian context according to Statistics Canada as reported in 2007 [3].

But what is men's health? Fletcher paraphrased the United States Public Health Service Action Plan for Women's Health by stating that “A men's health issue is a disease or condition unique to men, more prevalent in men, more serious among men, for which risk factors are different for men or for which different interventions are required for men" [4 p.68]. Examples of a unique disease in men would be prostate cancer; ischemic heart disease (more prevalent); osteoporosis (more serious); and sexual dysfunction (different treatment options).

During the course of a medical doctor's training, considerable time is spent on the teaching of medical issues related to women's health. The specialty field of Obstetrics and Gynecology is mainly responsible for teaching many of these issues. Currently, a minimum of three months out of a possible 24 months is dedicated to women's health in the urban family medicine training programs in Saskatchewan. This is comparable to most family medicine training programs in Canada. Almost no time is set aside for the teaching of medical issues unique to men. Some might say that this is the responsibility of the Urologists, but the field of Urology is not limited to dealing with problems of men only.

\section{Data Sources}

A review of traditional as well as gray literature and ephemera was undertaken using search terms such as: "male", "health education", "curriculum" and "family physician" and "general practitioner". Databases that were used include PubMed and Medline as well as a general search in Google Scholar. Websites of different family medicine training programs in Canada, the USA, Australia and the UK were also explored to find documentation on their curriculum. Lastly, references of various articles and textbooks on medical education were scanned for other possible references that could be used.

\section{Study Selection}

Initial search of Medline, Embase, Web of Science, Scopus and PubMed, using the MeSH terms mentioned above, produced the same two to three documents, all of which have been used in this review [5,6,7]. The references in these articles and website documents were scanned for more articles that might be relevant and those articles' references were also reviewed and so on. In the end a total of 108 articles and nine textbooks were reviewed.

\section{Synthesis}

The goal was to find publications that address the topic of men's health curricula in family medicine training programs. Since this was not a straight forward task, the literature that were found, were divided and analyzed in three distinct categories: curriculum in general, Family Medicine curriculum in Canada and the current status of men's health training in the world. These categories will now be discussed in more detail.

\section{Discussion}




\subsection{Curriculum}

It is difficult and even contentious to try and define what a curriculum is and/or should be. I use the term 'contentious' because a definition often puts limitations or boundaries on an idea.

Since the current practice of medicine is focused on the concept of EBM or "Evidence Based Medicine", it was only natural that medical education should follow the same trends. It was on this notion that Spady promoted the concept of "Outcome Based Education" or OBE [8]. According to Harden, Spady defined OBE as 'a way of designing, developing, delivering and documenting instruction in terms of its intended goals and outcomes" [9. P.37]. Harden went further and categorized the learning outcomes in a number of domains or skills. In a similar fashion, the Royal College of Physicians and Surgeons of Canada developed a framework with seven physician roles - the so-called CanMEDS competency framework [10].

\subsection{Family Medicine Curriculum in Canada}

The College of Family Physicians of Canada has, until recently, relied on individual programs to create their own curriculums based on the Standards for Accreditation of Residency Training Programs - the so-called "Red Book" [11]. Based on these standards, programs were expected to incorporate goals and objectives for different areas of family medicine, such as "Care of the Elderly", "Care of Adults", "Palliative and End of Life Care", etc. These goals and objectives had to be specific in the domains of knowledge, skills and attitudes and were expected to line up with the "Four Principles of Family Medicine":

1. The family physician is a skilled clinician;

2. Family medicine is community based;

3. The family physician is a resource to a defined practice population, and

4. The doctor-patient relationship is central to the role of the family physician.

The individual programs had to stipulate what methods were to be used for evaluating residents. Little detail was given as to how these goals and objectives were to be achieved.

Each of the seventeen medical schools in Canada has a family medicine residency training program responsible for the training of family physicians. This program has a minimum duration of two years and follows medical school. The curricula of these programs are mostly based on the standards for accreditation, set by the College of Family Physicians of Canada. (The Red Book) [11] A relevant quote from these standards reads: "To provide effective care, residents must become knowledgeable about the special health care requirements specific to men and women." [11](p16). Another relevant quote states that "Residents must be well acquainted with important physical and psychosocial aspects of men's and women's health care, including occupational health, family planning, spousal abuse, sexual assault, and sexual abuse. Residents must become familiar with gender-based differences in the management of common health problems in men and women." [11](p17).

In 2004, the College of Family Physicians of Canada published a document, "Family Medicine in Canada, Vision for the Future" [12]. In response to some of the recommendations made in the document, a Working
Group was created to review the postgraduate curriculum. In March 2011, this Working Group published a report, entitled: "Triple C Competency-based Curriculum" [13]. This outlined a curriculum that would be competencybased and was comprehensive, focused on continuity and centered in family medicine. The CanMEDS-FM framework was used as a guide to develop this curriculum [14].

Competency-based medical education is "an approach to preparing physicians for practice that is fundamentally oriented to graduate outcome abilities and organized around competencies derived from analysis of societal and patient needs" [15]. The CanMEDS-FM roles are defined as: Family Medicine Expert, Communicator, Collaborator, Manager, Health Advocate, Scholar and Professional [14].

\subsection{Current Status of Men's Health Training Globally and in Canada}

An extensive literature review was undertaken to better understand the status of men's health curricula in medical training programs around the world and then specifically in Canada. Although the body of literature on men's health is rapidly growing, little is written on the education of men's health in medical school curricula. The majority of the literature on these topics comes from Australia $[16,17]$ with some from the Netherlands [5], and the United Kingdom [18]. Studies in North America seem to focus on the education of more specific issues particularly that of homosexual and bisexual men [19]. Both the Royal College of General Practitioners (UK) and the Royal Australian College of General Practitioners created documents in 2007 that address a curriculum specific to the male sex $[18,20]$. The Department of Family Medicine at the University of Pennsylvania created a document entitled: "Recommended Curriculum Guidelines for Family Medicine Residents", which was endorsed by the American Academy of Family Physicians [6]. This document had some reference to men's health.

Rankin quotes Siebke in his article when he states that most women would know that problems related to being a woman are mostly dealt with by the specialty of Gynecology and Obstetrics [21]. This is not the case for men. Andrology has been proposed as the medical subspecialty that should manage most of the reproductive problems of men, and has attracted physicians from urology, endocrinology, internal medicine, dermatology, gynecology and geriatrics [21].

The study of "Andrology" is however too focused as it concentrates on the basic sciences of male physiology. One has to agree with Rankin that "As gynecology has done, this subspecialty should expand and move beyond male reproductive health and establish itself as a specialty encompassing all gender-specific aspects of men's health: from mental health and psychosocial aspects to physical health." [21](p48). Rankin coined the term "modified andrology" that would include more than just reproductive health.

Australia is without doubt the country that has so far set the standards for men's health in the world. In 2001, the Australian government established "Andrology Australia" to increase the level of awareness about male reproductive issues [22]. Australia was also the first country to have a dedicated men's health nurse practitioner [23]. This was a 
very positive step forward. It was mentioned already that most people believe that Urology should be the field that deals with men's health. Urologists are without doubt more equipped to deal with the more complex issues around men's renal and reproductive systems, but the argument was already made that men's health consists of more than just their sexual function. Family Medicine is the discipline that deals with individuals of both sexes, all ages and in all stages of their life cycles.

"Comprehensive care is an important tenet of family practice and involves full-service health care of both sexes and all ages 'from conception to resurrection.' Because Family Physicians emphasize that the patient should receive appropriate care at the right place and at the right time, they place a high premium on coordinated care" [23].

The content of a men's health curriculum is of much debate. There is disconnect between what services health care providers think should be offered at a "men's health clinic" and what the patients think. Patients of different ages also have different needs when it comes to their health $[19,21,25,26]$.

There are a huge variety of foci in the content of the curricula in medical schools that do offer a men's health curriculum. On the one end of the spectrum, the men's health curriculum of the Royal Australian College of General Practitioners is very general in its approach and does not go into detail concerning the different topics that should be covered [20]. Only examples of conditions are given under the five domains of general practice: communication skills, applied professional knowledge, population health, professionalism and ethics, and organizational and legal dimensions.

On the other end of the spectrum, the American Academy of Family Physicians published recommended curriculum guidelines for family medicine residents [6]. In its document on men's health, there are long lists of conditions that can affect men's health but are not unique to only males [6]. And then there is the Hawaiian Residency Program website that has a men's health curriculum listed under the Internal Medicine program [27]. No mention is made in this curriculum of conditions that affect young boys and their pediatric program does not contain anything specific to male health.

All of the curricula have one thing in common: very little information is given on how the students will acquire the stated objectives listed in the documents. It is one dimension to determine what skills should be acquired but a different yet complementary dimension to ascribe how they might or should be acquired.

A further aspect of any curriculum is that of assessment. First there is the assessment of the learner but also then the assessment of the curriculum. Harden simplifies the various aspects of learner assessment into six questions: Who, why, what, how, when and where [9]. Various tools can be employed to assess learners, such as written exams, clinical exams, observations, peer assessments and portfolios to name just a few [28]. Whatever method of assessment is chosen in the end, it should align with the type of curriculum that is used - in the case of Family Medicine Residency Programs, a competency based curriculum.

\section{Conclusion}

Education in men's health appears to be a neglected topic in practice as well as in the literature. Efforts have been made by some medical schools in the world to focus some attention on the unique issues that affect men and how they can optimally be taught to medical students and residents. The curricula however lack detail on male specific problems and procedures, as well as, exactly how such content could be optimally taught to future physicians as well as be evaluated. There seems to be a paucity of literature on what is happening in Canadian medical schools when it comes to men's health curriculum.

\section{References}

[1] Mathers CD, Sadana R, Salomon JA, Murray CJ, Lopez AD. Healthy life expectancy in 191 countries. The Lancet. 2001; 357(9269):1685-1691.Statistics Canada [Internet].

[2] Dodson, DC. Men's health compared with women's health in the 21 st century USA. The Journal of Men's health and gender. 2007; 4(2): 121-123.

[3] Ottawa: Statistics Canada; 2007 [cited 2011 Aug 8]. Available from http://www.statcan.gc.ca/.

[4] Fletcher R. The development of men's health in Australia. In: Davidson N, Lloyd T, editors. Promoting men's health. A guide for practitioners. London: Bailliere Tindall, 2001; p68.

[5] Verdonk P, Mans LJL, Lagro-Janssen ALM. Integrating gender into basic medical curriculum. Medical Education. 2005; 39: 1181125.

[6] American Academy of Family Physicians [Internet]. Kansas; 2010 [cited 2011 Aug 8] Available from

http://www.aafp.org/online/etc/medialib/aafp_org/documents/abou t/rap/curriculum/menshealth.Par.0001.File.tmp/Reprint257.pdf.

[7] Dielissen PW, Bottema BJAM, Verdonk P and Lagro-Janssen TLM. Incorporating and evaluating an integrated gender - specific medicine curriculum: a survey study in Dutch GP training. BMC Medical Education. 2009;9(1):58-65.

[8] Spady WG. Outcome-based education: Critical issues and answers. Virginia: American Association of School Administrators, 1994.

[9] Harden RM, Laidlaw JM. Essential skills for a medical teacher. An introduction to teaching and learning in medicine. Dundee: Churchill Livingstone Elsevier, 2012; p35-53.

[10] The Royal College of Physicians and Surgeons of Canada. (2005) CanMEDS: better standards, better physicians, better care. [Internet]. Ottawa; 2006 [cited 2012 June 8] Available from http://www.royalcollege.ca/public/resources/aboutcanmeds.

[11] The College of Family Physicians of Canada. (2006). Standards of training for residency training programs. [Internet]. Mississauga; 2006 [cited 2011 Aug 8] Available from

http://www.cfpc.ca/uploadedFiles/Red\%20Book\%20English.pdf.

[12] The College of Family Physicians of Canada. (2004). Family medicine in Canada: A vision for the future. [Internet]. Mississauga; 2004 [cited 2012 May 23] Available from http://www.cfpc.ca/uploadedFiles/Resources/Resource_Items/FA MILY_MEDICINE_IN_CANADA_English.pdf.

[13] Tannenbaum D, Kerr J, Konkin J, Organek A, Parsons E, Saucier D, Shaw L, Walsh A. Triple C competency-based curriculum. Report of the working group on Postgraduate curriculum reviewPart 1. Mississauga, ON: College of Family Physicians of Canada; 2011.

[14] Tannenbaum D, Kerr J, Konkin J, Organek A, Parsons E, Saucier D, Shaw L, Walsh A. Triple C competency-based curriculum. Report of the working group on Postgraduate curriculum reviewPart 1. Mississauga, ON: College of Family Physicians of Canada; 2011. Appendix 1.

[15] Frank JR, Mungroo A, Ahmed Y, Wang M, De Rossi S, Horsley T Towards a definition of competency-based education in medicine: a systematic review of published definition. Med Teacher. 2010; 32:631-7.

[16] Lumb P. Why is men's health and well-being policy not implemented in Australia? International Journal of Men's Health. 2003; 2(1):73.

[17] Gregory AT, Lowy MP, Zwar NA. Men's health and wellbeing: taking up the challenge in Australia. The Medical Journal of Australia. 2006; 185(8):411. 
[18] Royal College of General Practitioners [Internet]. London; 2007 [cited 2011 Aug 8] Available from http://www.rcgpcurriculum.org.uk/extras/curriculum/statementDetails.aspx?id=18

[19] Tesar CM, Rovi SLD. Survey of Curriculum on Homosexuality / Bisexuality in Departments of Family Medicine. Educational Research and Methods. 1998; 30(4):283-287.

[20] The Royal Australian College of General Practitioners [Internet]. Melbourne; 2007 [cited 2011 Aug 8] Available from http://www.racgp.org.au/scriptcontent/curriculum/pdf/menshealth. pdf.

[21] Rankin TL. Andrology as the medical specialty to focus medical training on men's health. The Journal of Men's health and gender. 2005; 2 (1): 45-48.

[22] Wijesinha, SS. GP's as medical educators. An Australian trainthe-trainer program. Australian Family Physician. 2008; 37(8):684-688

[23] Anonymous. A first for men's health. Australian Nursing Journal. 2007; 15(1):33.
[24] Taylor, RB. (Ed) Family Medicine: Principles and Practice (6th ed.). New York: NY. Springer-Verlag New York, Inc; 2003.

[25] Porche, DJ, Willis, DG. Nursing and men's health movement: considerations for the 21st century. Nursing clinics of North America. 2004; 39:251-258

[26] Rogers WM, Harb K, Lappin M, Colbert J. College Men's Health in Practice: A Multidisciplinary Approach. Journal of American College Health. 2000; 48 (6): 283-288.

[27] Hawaii Residency Programs. INC. [Internet]. Hawaii. 2008 [cited 2011 December 26] Available from http://www.hawaiiresidency.org/images/stories/InternalMed/docs/ 17\%20mens\%20health\%202008.pdf?phpMyAdmin=P7RdtwRgQ auYRpOevaKoBjk7MZb.

[28] Shumway JM, Harden RM. AMEE Education Guide No 25: The assessment of learning outcomes for the competent and reflective physician. Medical Teacher. 2003; 25(6):569-584. 